\title{
POPULAÇÃO CAIÇARA, MATA ATLÂNTICA E SITUAÇÃO ATUAL DO PALMITO-JUÇARA (Euterpe edulis MART.) NA REGIÃO DO RIO UNA DA ALDEIA (IGUAPE-SP), ENTORNO DA ESTAÇÃO ECOLÓGICA JUREIA-ITATINS ${ }^{1}$
}

Clovis José Fernandes de Oliveira Junior², Yago Tauá Rodrigues das Neves² e Paula Soares Junqueira²

\begin{abstract}
RESUMO - Neste trabalho foram desenvolvidos estudos na região do Rio Una da Aldeia, afluente do ribeira de Iguape, no entorno da Estação Ecológica Jureia-Itatins, Município de Iguape, São Paulo. Esses estudos consistiram de levantamento em campo das populações de Euterpe edulis Mart. (palmito-juçara) e também de estudos preliminares etnobotânicos, através da aplicação de questionários semiestruturados e realização de seminário para diagnóstico do uso atual da área, sensibilização e percepção da sustentabilidade ambiental pelos comunitários. O trabalho teve como objetivos avaliar o estado de conservação das populações do palmito-juçara e também estudar relações que as comunidades caiçaras da região mantinham com o ambiente natural. Os resultados indicaram a urgente necessidade de elaboração de um plano para enriquecimento e manejo de Euterpe edulis Mart. Foi constatada também a imensa potencialidade de uso econômico da floresta, bem como o desejo das populações tradicionais em manejar sustentavelmente os recursos naturais.
\end{abstract}

Palavras-chave: Euterpe edulis, Desenvolvimento sustentável e Mata Atlântica.

\section{CAIÇARA COMMUNITIES, ATLANTIC FOREST AND ACTUAL SITUATION OF THE PALMITO JUÇARA (Euterpe edulis MART.) AROUND RIVER UNA DA ALDEIA (IGUAPE, SP) SURROUNDING ESTAÇÃO ECOLOGICA JUREIA-ITATINS}

\begin{abstract}
In this work, studies were developed in the Una da Aldeia river region, an affluent of the Ribeira de Iguape in the surroundings of Estação Ecológica Jureia-Itatins, Iguape, São Paulo. The studies consisted of a survey of the population of Euterpe edulis Mart. (palmito-juçara) situation and of preliminary ethnobotanical studies by means of the semistructured questionnaire application and realization of seminary for the diagnosis of the area use and for local people sensitization and perception of the environment sustainability. The aim of this study was to evaluate the conservation situation of the population of palmito-juçara and also to study the relationship that the local caiçara communities keep with the natural environment. The results obtained show the urgent necessity of elaborating a plan for the enrichment and management of Euterpe edulis Mart. The immense potentiality of the forest economic use was also verified, as well as the traditional populations wish of managing sustainably natural resources.
\end{abstract}

Key-words: Euterpe edulis, sustainable development and Atlantic Rain Forest.

\section{INTRODUÇÃO}

A gestão e manutenção das Unidades de Conservação (UCs) de uso restrito, criadas para a preservação dos recursos naturais e de ecossistemas exemplares, têm apresentado problemas de difícil solução (ARRUDA, 1999, 2000; LIMA et al., 2005). Uma das principais dificuldades refere-se às populações humanas que já habitavam a área antes da sua apropriação pelo Estado(ARRUDA, 1999, 2000; DIEGUES, 2004). Acriação de áreas naturais protegidas em territórios ocupados por sociedades tradicionais é vista, por essas populações, como violação de seus direitos à terra. Essas comunidades mantêm relação íntima com o ambiente natural que, segundo Diegues (2004), lhes fornece os meios de subsistência, de trabalho e produção, além de produzir os aspectos próprios das relações sociais, que compõem a estrutura de sua sociedade e permitem sua existência como grupo portador de determinada cultura.

\footnotetext{
${ }^{1}$ Recebido em 04.06.2008 e aceito para publicação em 25.08.2010.

${ }^{2}$ Instituto de Botânica, IBT, Brasil. E-mail: <floraacao@gmail.com>.
} 
O modelo de desenvolvimento adotado no Brasil e utilizado até nossos dias demonstrou-se inadequado, provocou alterações nos biomas, com redução de áreas naturais, extinção de espécies e diminuição da disponibilidade de recursos naturais. A expulsão dos moradores tradicionais das áreas de preservação e a proibição dos usos que faziam dos recursos naturais, em muitos casos, acentuaram o processo de degradação das áreas (ADAMS, 2000).

A adoção do manejo sustentável nas zonas de amortecimento das UCs, visando à manutenção da biodiversidade, é instrumento fundamental para as comunidades tradicionais (ALBUQUERQUE, 2005ab), as quais dependem, em maior ou menor grau, das áreas naturais para sua sobrevivência. Como visto, os problemas para conservação da diversidade biológica não estão apenas na biologia e ecologia das espécies, mas também nos âmbitos político, social e econômico das pessoas envolvidas. Na busca de novas formas de gestão, o grande desafio será conciliar as necessidades das comunidades humanas envolvidas com a necessidade de se preservar a diversidade biológica e os sistemas naturais (ARRUDA, 1999, 2000; SILVA et al., 2004).

Manejar os recursos naturais em área de floresta tropical é um desafio complexo, principalmente por não se conhecer largamente a biologia e ecologia das espécies, nem o contexto social e ambiental das áreas em questão. “A preservação da diversidade biológica passa pela conservação da diversidade cultural, é necessário conservar a experiência histórica e cultural da convivência das populações tradicionais com a Mata Atlântica” (LINO, 1992). Muitas vezes, as comunidades locais conhecem a dinâmica dos ecossistemas e das espécies presentes na região (BENSUSAN, 2006).

Como estratégia de ação para proteção das UCs, destaca-se a exploração dos recursos naturais em seus entornos, por meio de extrativismo e produção sustentável (ARRUDA, 2000; DIEGUES e VIANA, 2004; ALBUQUERQUE, 2005a). Entre as ações no entorno, destacam-se o diagnóstico dos sistemas agrícolas e extrativistas praticados pelos moradores e também a identificação de projetos de interesse (OLIVAe MAGRO, 2004). Deve-se considerar também que o palmito-juçara é um dos mais abundantes e valiosos produtos não madeireiros da Mata Atlântica (CALVI et al., 2004; CALVI e PINA-RODRIGUES, 2005; FANTINI e GURIES, 2007).
Além de seu valor econômico e alimentício, o palmiteiro é também considerado de extrema importância ecológica na cadeia alimentar do ecossistema florestal (GALETTI e ALEIXO, 1998) e a abundante produção de frutos e a gama de animais que deles se alimentam durante parte do ano caracterizam a espécie como mutualistachave (MARTINS e LIMA, 1999).

Metodologias de pesquisa-ação (THIOLLENT, 2007) têm sido aplicadas em diversos campos de atuação, como educação, comunicação, organização e difusão de tecnologia rural, entre outras, e supõem uma forma de ação planejada de caráter social e educativo. Um de seus principais objetivos é fornecer aos pesquisadores e grupos participantes os meios pelos quais sejam capazes de responder, com maior eficiência, aos problemas da situação vivenciada, em particular sob a forma de diretrizes da ação transformadora. Trata-se de facilitar a busca de soluções aos problemas reais para os quais os procedimentos convencionais têm pouco contribuído. Essas metodologias têm sido aplicadas em estudos de comunidades geograficamente concentradas.

O objetivo deste trabalho foi realizar levantamento das populações de Euterpe edulis Mart., visando estudos para futura produção sustentável, além de estudos das relações entre as comunidades locais e o ambiente natural, procurando avaliar o potencial de utilização econômica da biodiversidade no entorno da UC, bem como a percepção que os comunitários detêm sobre a sustentabilidade dos recursos naturais, bem como seus anseios quanto ao uso econômico da biodiversidade.

\section{MATERIAL E MÉTODOS}

Área estudada - A área de estudo abrange as comunidades Aldeia do Una e Costeira da Barra

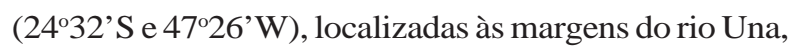
afluente do Ribeira de Iguape, no Município de Iguape, SP, o qual se situa aproximadamente a $200 \mathrm{~km}$ da cidade de São Paulo, no litoral Sul do Estado. O município abrange 79,25\% da Estação Ecológica Jureia-Itatins e abriga também as Estações Ecológicas Banhado Grande e Banhado Pequeno.

Levantamento de campo das populações de Euterpe edulis Mart. - Para estimativa das populações de palmito-juçara foram delimitadas 10 parcelas de $625 \mathrm{~m}^{2}$ cada ( $25 \times 25 \mathrm{~m}$ ), sendo cinco na região da Comunidade da Aldeia do Una e cinco na região da Costeira da Barra. Foram quantificadas todas 
as plântulas de até $50 \mathrm{~cm}$ de altura; acima desse valor, as plantas foram também mensuradas quanto à altura e ao diâmetro à altura do peito (DAP).

Questionários - Questionários semiestruturados foram aplicados por unidade familiar, num total de 47 questionários, sendo 34 na Costeira da Barra e 13 na região da Aldeia. Os questionários visaram identificar o feitio de roças, a retirada de produtos da floresta para alimentação e matéria-prima para manufatura de ferramentas e artesanatos.

Seminário para sensibilização e percepção ambiental - Foram apresentados dois vídeos que tratavam de desenvolvimento sustentável em outras comunidades tradicionais. Após a exibição dos vídeos, os comunitários foram divididos em grupos para interpretação, reflexão e discussão. Também foi orientado que eles realizassem uma autocrítica, focada nas relações que a comunidade mantém com as áreas naturais e consigo própria. No final cada grupo apresentou suas impressões e posicionamento para todos, promovendo uma discussão geral.

\section{RESULTADOS E DISCUSSÃO}

A Tabela 1 apresenta os resultados referentes ao levantamento das populações de Euterpe edulis Mart., popularmente conhecido como palmito-juçara. Através de sua análise, pode-se notar claramente a diferença da situação em cada área, tanto em relação ao número de plântulas quanto ao tamanho das plantas maiores que $50 \mathrm{~cm}$. Foi constatado que as duas áreas estudadas necessitam de um plano de enriquecimento, visto que nenhuma atingiu o mínimo estabelecido pela Resolução SMA/SP, de 16/1994 (estabelece normas para exploração do palmeira-juçara, Euterpe edulis, no Estado de São Paulo, 21/06/1994), que é de 5.000 plântulas por hectare.
Na região da comunidade da Aldeia do Una, o levantamento confirmou a grande diminuição das populações de palmito e a área sofre intenso processo de interferência humana devido à presença da comunidade local e, também, à presença, no passado, de empresas voltadas para exploração comercial do palmito-juçara. Esse processo levou a um grande empobrecimento da espécie na região.

A região amostrada na comunidade da Aldeia do Una apresenta grande diversidade de relevos, com morros, encostas (declividade acentuada a média e normalmente utilizadas para o plantio de mandioca) e desmontes (declividade baixa, localizados nos sopés dos morros e que recebem sedimentos de áreas mais altas) e áreas de planície ou baixio, utilizadas para cultivo de arroz. Historicamente, a região tem ocupação humana milenar, sendo constatada pela presença de sambaquis ou casqueiras. Atualmente, as populações locais ocupam a área provavelmente há bem mais de 100 anos, o que resultou numa grande interferência antrópica, apresentando, assim, muitas áreas com características de vegetação secundária.

A região estudada na comunidade da Costeira da Barra situa-se dentro de propriedades particulares e se caracteriza por topografia de baixas altitudes, mais ou menos horizontalizada, constituída de regiões de baixada, mais úmidas e lombadas, um pouco mais altas e, por isso, mais secas. De modo geral, apresenta perfil bastante homogêneo, exibindo em quase toda a sua extensão intensa forração de bromélias de várias espécies, com grande potencial para aproveitamento econômico. Espécies da família Bromeliaceae produzem sementes abundantemente, e poucos frutos podem dar origem a milhares de novas plantas, considerando também que muitas espécies se propagam facilmente de forma vegetativa. Apesar de essas espécies apresentarem crescimento lento, a atividade pode ser excelente

Tabela 1 - Estimativa da população de palmito-juçara (Euterpe edulis) na região do Rio Una da Aldeia, Município de Iguape, SP. Table 1 - Population estimation of palmito-juçara (Euterpe edulis), in the region of Una da Aldeia River, Iguape, SP.

\begin{tabular}{|c|c|c|}
\hline & $\begin{array}{c}\text { Comunidade } \\
\text { Aldeia do Una }\end{array}$ & $\begin{array}{c}\text { Comunidade da } \\
\text { Costeira da Barra }\end{array}$ \\
\hline Número médio de plântulas por hectare (até 50 cm de altura) & 179 a & $2840 \mathrm{~b}$ \\
\hline Número médio de indivíduos por hectare (acima de 50 cm) & 205 a & 227 a \\
\hline - Altura média (m) & 2,17 a & $3,69 \mathrm{~b}$ \\
\hline - Diâmetro médio (cm) & 2,72 a & $6,41 \mathrm{~b}$ \\
\hline
\end{tabular}

As letras comparam médias entre as comunidades (Tukey p<0,05).

Como médias letras comparam empreendedorismo como comunidades (Tukey p<0,05).

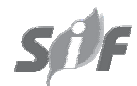

Revista Árvore, Viçosa-MG, v.34, n.6, p.1065.1073, 2010 
alternativa para geração de renda no médio e longo prazos. No Brasil (HEIDEN et al., 2006), plantas como orquídeas, bromélias e algumas samambaias são obtidas de forma extrativista, insustentável, ilegal e comercializadas, apesar dos riscos de autuação, de não adaptação do produto fora do ambiente natural e dos danos causados a esse ambiente. Tal fato pode ser indicativo de que, se inseridas na cadeia produtiva, dentro das leis ambientais e de proteção, as plantas nativas são capazes de ocupar espaço crescente no mercado da floricultura e paisagismo, por seus requisitos diferenciais. Além disso, a inserção de espécie vegetal em cultivo é uma forma de conservação $e x$-situ e ajuda a despertar interesse na sua preservação à medida que aumenta sua visibilidade e importância econômica (HEIDEN et al., 2006).

As duas áreas amostradas apresentam perfis bastante distintos, embora ambas estejam bastante antropizadas, a área levantada na Costeira da Barra apresenta populações de palmito em melhores condições não somente pelo maior vigor das plantas medidas, que pode ser verificado pela média de altura e diâmetro dos indivíduos (Tabela 1), como pelo número de plântulas por hectare, que é mais de 10 vezes maior que a área da Aldeia. A altura e o diâmetro médio das plantas maiores que $50 \mathrm{~cm}$ apresentam grande diferença entre as duas áreas, e essa diferença pode ser facilmente explicada pelos fatos de que a região da Costeira da Barra é caracteristicamente de baixada, apresentando solo bastante turfoso e úmido, proporcionando bom crescimento e desenvolvimento das plantas, e também porque a área em questão se encontra no interior de propriedades particulares, recebendo cuidados periodicamente. Essa área se encontra próxima de uma área explorada comercialmente no passado e apresenta numerosos indivíduos em fase de frutificação, auxiliando muito o processo de dispersão de sementes e manutenção do banco de plântulas. Vale ressaltar que, mesmo se tratando de propriedade particular, os proprietários reclamam de constantes invasões para roubo de palmito, fator determinante para degradação de suas populações.

É interessante observar que, de modo geral, na área da Aldeia do Una muitos dos palmitos mensurados são do tipo “fino” e, segundo os caiçaras, não são cortados, pois o palmito é de baixa qualidade e amargo, persistindo na região, enquanto os palmitos mais grossos, em quase a totalidade das vezes, são cortados ainda pequenos.
O melhor vigor dos indivíduos de palmito na área da Costeira da Barra, quando comparada com a área da outra comunidade amostrada, demonstra que pequenos cuidados no cultivo já apresentam retorno no crescimento das plantas, ressaltando-se a aptidão e o potencial produtivo do palmiteiro, e a implantação de projetos para manejo sustentável da espécie trará grandes ganhos na conservação do palmito-juçara. Segundo Martins e Lima (1999), a palmeira $E$. edulis desenvolve-se bem em regiões tropicais e subtropicais, com elevado índice pluviométrico. De modo geral, não é exigente quanto ao tipo de solo, porém não se adapta bem a solos rasos e encharcados; apresenta excelente desenvolvimento nas matas pluviais da costa atlântica.

Atualmente, o extrativismo clandestino do palmitojuçara é um dos principais conflitos na gestão das áreas naturais, não sendo raros os confrontos armados entre extrativistas, agentes de vigilância e seguranças de propriedades. Segundo o DEPRN, apenas as ocorrências registradas somam mais de 200 por ano (SALES et al., 2004). Em estudos realizados por Galetti e Fernandez em 1998, foi estimado que eram colhidos ilegalmente cerca de 60 mil juçaras por ano, e infelizmente existe carência de informações que possam retratar essa condição nos dias de hoje.

Através da análise dos questionários (Tabela 2), foi identificado que as populações locais mantêm relações estreitas com a floresta e apresentam dependência da mata para alimentação e manufatura de utensílios e ferramentas. Entretanto, vale ressaltar que, como a retirada de material da floresta é proibida por lei, algumas informações podem ter sido omitidas. Muitos dos entrevistados relataram que ainda fazem capina de modo orgânico, com pequenos desmatamentos, agricultura itinerante de corte e queima ou roça de coivara, que, segundo Canelada e Jovchelevich (1992) e Oliveira et al. (1994), retornam ao processo de sucessão ecológica sem prejuízo quando abandonadas. Entre aqueles que disseram que não faziam roça, muitos a faziam, e deixaram de fazer apenas por causa da proibição legal depois da criação da Estação Ecológica, embora seja possível solicitar aos órgãos competentes autorização para fazê-la. A agricultura itinerante, no entanto, nem sempre poderá ser realizada sem prejuízos, pois apresenta limitações, principalmente, no que se refere à densidade populacional humana da região (ADAMS, 2000). 
Como pode ser observado na Tabela 2, a coleta na floresta para fins alimentícios foi constatada em $71 \%$ das unidades familiares, e a grande maioria citou o palmito em primeiro lugar, seguido de caça e frutos em geral. É interessante observar que durante a aplicação dos questionários, em conversas informais, foi percebido que parte dos entrevistados tinha consciência da diminuição na quantidade de indivíduos nas populações do palmito-juçara, porém não preservavam matrizes, pois alegaram também a frequente retirada de juçaras por pessoas não pertencentes à comunidade.

Deve-se considerar que os antepassados tinham relação ainda mais estreita com a floresta (ADAMS, 2000). De acordo com Sanches (2005), a grande maioria das pessoas residentes na área da Jureia vivia da extração do palmito e da caxeta, do cultivo de roças e da pesca artesanal. Deve-se ressaltar, também, que a mudança desses hábitos deveu-se, principalmente, à criação da Estação Ecológica. A proibição por lei da extração do palmito e caxeta fez que a atividade tradicional se tornasse clandestina, e por isso feita com mais pressa, menos consciência e seletividade, prejudicando ainda mais as populações dessas espécies vegetais.

A realização do seminário foi importante para diagnosticar a posição e interesse das comunidades em manejar sustentavelmente as áreas naturais e, também, para construção de uma visão geral de seu estado atual de conservação. Como resultados, foram destacados os seguintes pontos pelos comunitários: a necessidade de elaboração de plano de manejo para o palmito, com definição de áreas para descanso e recuperação; a necessidade de instalação de viveiro comunitário para produção de mudas de palmito e outras espécies arbóreas, sendo sugerido, inclusive, o estabelecimento de cotas de colheita para quem trabalhar no viveiro e no plantio; a necessidade de cursos de capacitação com instrutores comunitários para transmissão dos conhecimentos tradicionais, como: manufatura de viola, rabeca, cestos, esteiras, pilão, remo, covo, vassoura de timbopeva e outros; a necessidade de cursos de capacitação com agentes externo, por exemplo, curso de apicultura, pois alguns comunitários já vêm trabalhando com produção de mel; e anseio do resgate cultural da produção de farinha de mandioca nas unidades familiares, as casas de farinha, a necessidade da presença do Estado na área para fiscalização da entrada de estranhos, pois é comum a retirada de recursos naturais por pessoas que não são da comunidade, além da manutenção das estradas.

Na Tabela 3 são sumarizadas as categorias de usos da vegetação nativa, sintetizando diversas espécies em diferentes categorias de usos. O conhecimento adquirido no uso das plantas nativas vem sendo construído há muito tempo, sendo transmitido de geração para geração, em quase a sua totalidade, oralmente. Através dessas observações, é possível identificar o grande potencial de produtos da floresta, que juntamente com o palmito-juçara poderão constituir alternativas para geração de renda e melhorias da qualidade de vida nas comunidades. Recomendações do trabalho de Galetti \& Fernandez (1998) apontam para a necessidade da diversificação da economia local, incentivos para pequenos proprietários rurais para produzir juçara e outras palmeiras que forneçam palmito e também a instalação de um processo de monitoramento das populações de Euterpe edulis e fauna associada.

Rossato (1996) descreveu o grande conhecimento que populações caiçaras detêm a respeito da utilização da Mata Atlântica, sugerindo a possibilidade de exploração econômica sem grandes prejuízos à diversidade biológica. Botrel et al. (2006) também descreveram o conhecimento que populações locais

Tabela 2 - Atividades de usos da floresta pelas comunidades Costeira da Barra e Aldeia do Una (Iguape, SP), entorno da Estação Ecológica Jureia-Itatins.

Table 2 - Useful activities of the forest by the communities of Costeira da Barra and Aldeia do Una (Iguape, SP), surroundings of Estação Ecológica Jureia-Itatins.

\begin{tabular}{|c|c|}
\hline Atividade & $\begin{array}{c}\text { Porcentagem das unidades } \\
\text { familiares que desenvolve } \\
\text { a atividade } \\
\end{array}$ \\
\hline Roça (mandioca, milho, melancia, arroz, feijão, banana, maracujá e hortaliças). & $50 \%$ \\
\hline Coleta na floresta para alimentação (palmito, caça e frutos em geral). & $71 \%$ \\
\hline $\begin{array}{l}\text { Manufaturas a partir de plantas da floresta (artesanatos e ferramentas: cestos, balaios, } \\
\text { remo, canoa, pilão, cabos, vassoura e rabeca). }\end{array}$ & $50 \%$ \\
\hline
\end{tabular}


Tabela 3 - Categorias de uso do saber tradicional da vegetação nativa pelas comunidades Aldeia do Una e Costeira da Barra, Iguape, entorno da Estação Ecológica Jureia-Itatins.

Table 3 - Categories of traditional knowledge uses for native plants by the comunities Aldeia do Una and Costeira da Barra (Iguape), surroundings of Estação Ecológica Jureia-Itatins.

\begin{tabular}{ccc}
\hline Categoria de uso & Tipos de usos mencionados & $\begin{array}{c}\text { Número de espécies } \\
\text { de conhecimento } \\
\text { popular citadas }\end{array}$ \\
\hline Alimentícia & Alimentação humana & 14 \\
Ambiental & Alimentação fauna \\
Construção & Vigas, caibros, cercas, tábuas, esteio & 23 \\
Energia & Lenha & 30 \\
Manufaturas & Canoa, remo, cabo de ferramentas, cestas, \\
& balaios, peneira, tipiti, gamela, pilão, esteira, \\
Medicinais & vassoura, cerco, covo, viola e rabeca \\
Ornamentais & - & 36 \\
Outros usos & Óleo lubrificante, resina, cola, fio para rede de pesca \\
\hline
\end{tabular}

mantêm sobre os remanescentes vegetais e colocaram que o conhecimento popular sobre o uso das espécies nativas pode contribuir para a conservação dos ecossistemas no que diz respeito à adoção de práticas de manejo, além de contribuir para o resgate e preservação da cultura popular.

Para Diegues (2004), o que se propõe para a criação de uma nova ciência da conservação é uma síntese entre o conhecimento científico e o tradicional. Para tanto, é preciso reconhecer a existência, entre as sociedades tradicionais, de outras formas igualmente racionais de se perceber a biodiversidade, além daquelas oferecidas pela ciência moderna.

As categorias de uso tradicional (Tabela 3) fornecem apenas uma ideia da imensa potencialidade de produtos da floresta que podem ser aproveitados economicamente. É preciso ressaltar que, além da coleta e identificação botânica das espécies utilizadas, é necessário o registro do conhecimento tradicional das comunidades. Para isso, deve-se ter a concordância delas através da anuência prévia e de registros no IBAMA/SISBIO, visando à proteção ao conhecimento tradicional e garantias à repartição de benefícios, conforme determina a legislação (AZEVEDO, 2005). Além disso, são necessárias estabelecer normas para manejo para cada espécie a ser trabalhada e essas normas nem sempre poderão ser estabelecidas num curto prazo em razão, principalmente, da falta de conhecimento científico sobre a dinâmica e crescimento populacional das espécies nativas, porém são fundamentais para a instalação do processo de produção sustentável.
Além do pouco conhecimento que a ciência detém sobre a dinâmica do crescimento e desenvolvimento das espécies nativas, pouco se sabe, também, sobre a relação que as populações locais mantêm com as áreas naturais, de vegetação nativa. Logo, a implantação do modelo de desenvolvimento sustentável contribuirá, de maneira definitiva, na expansão da consciência na busca de equilíbrio ambiental. É a garantia de um processo de gestão que preestabelece normas para monitorar e avaliar constantemente a preservação dos direitos sociais econômicos e ambientais. O modelo Reserva de Desenvolvimento Sustentável (RDS) pode conduzir a um estreitamento das relações entre comunidades tradicionais e científicas e também com o poder público. Segundo Scarano (2007), as vias de comunicação entre cientistas e os tomadores de decisão, na definição de políticas públicas, devem ser aprimoradas para efetivamente se reverter o quadro de destruição da biodiversidade, pois foi constatado e discutido que a ciência acadêmica em biodiversidade aumentou enormemente em quantidade e em qualidade nos últimos anos, porém a destruição de habitats nos grandes biomas brasileiros se mantém em taxas alarmantes.

O plano de desenvolvimento sustentável para o entorno da Estação Ecológica de Assis (MAX et al., 2007) apontou importantes resultados não previstos na proposta inicial: o conhecimento sobre a região do entorno foi ampliado e proporcionou a montagem de um banco de dados bastante importante para a região; possibilitou a capacitação de estagiários e o aprimoramento do corpo técnico dos órgãos envolvidos; as atividades desenvolvidas proporcionaram também

Revista Árvore, Viçosa-MG, v.34, n.6, p.1065.1073, 2010 
a ampliação da confiança das comunidades em relação aos técnicos da Unidade, abrindo a possibilidade de futuros trabalhos comuns. Em Mamirauá, o modelo RDS resultou em importantes ganhos nos seus 15 anos de existência, tanto do ponto de vista da conservação da biodiversidade quanto do desenvolvimento da qualidade de vida da população tradicional que habitava a reserva (QUEIROZ, 2005).

Ainda segundo Queiroz (2005), as alternativas econômicas de baixo impacto ambiental objetivaram a valorização dos produtos da biodiversidade local, e as normas de manejo devem ser estruturadas de modo a garantir a sustentabilidade financeira das populações. Sachs (2007) apontou que condição necessária para o desenvolvimento é ter o crescimento econômico colocado a serviço de objetivos socialmente desejáveis, incluindo a minimização dos impactos ambientais. Gomes et al. (2006) discutiram o papel e responsabilidade social de empresas, principalmente as de exploração florestal, concluindo que projetos de fomento florestal com geração de emprego e renda contribuem para a agregação de valores sustentáveis para as empresas e para a sociedade.

Partindo-se do ponto de vista da economia ecológica, a ideia é de que os sistemas ecológicos e econômicos sejam considerados sistemas vivos, complexos e adaptativos e que necessitam ser estudados como sistemas integrados, sobretudo ao se apreciar que a necessidade de informação sobre interações entre a economia e o ecossistema tem como objetivo a identificação de políticas capazes de mitigar os impactos destrutivos sobre o ambiente e de realizar o bem-estar social (CAVALCANTI, 2003).

\section{CONSIDERAÇÕES FINAIS}

Através dos resultados alcançados com este trabalho, entende-se que o manejo sustentável do palmito é possível e desejável pelas comunidades, porém, devido ao estado atual de suas populações nas áreas em questão, é necessário primeiro que se faça um plano para repovoamento visando ao futuro manejo. Rendimentos econômicos advindos de processo para produção sustentável somente serão possíveis no médio e longo prazos. Apesar disso, é bastante importante o estabelecimento imediato de um plano de manejo para essa espécie, assim como é desejável e imprescindível a presença do Estado, principalmente no que se refere à fiscalização das áreas. Marcos e Matos (2003) entenderam que o manejo sustentável do palmito é caminho necessário para a conservação da espécie.
Os resultados obtidos com a aplicação dos questionários e também pela realização do seminário indicaram claramente que os comunitários têm conhecimento do estado atual de conservação da área e desejam reverter a situação. Esses resultados partiram de pesquisas de ação participativa e, como conceituado por Thiollent (2007), é concebida e realizada em estreita associação com ação ou com a resolução de problema coletivo, em que os pesquisadores e os participantes representativos da situação ou do problema estão envolvidos, de modo cooperativo ou participativo.

A instalação do modelo RDS traz possibilidades para o estudo do conhecimento tradicional adquirido nos últimos séculos, proporciona possibilidades para estudo e acompanhamento do estado de conservação e preservação da área natural; cria condições para incrementar estudos e desenvolver conhecimentos sobre a ecologia, dinâmica e crescimento da vegetação nativa. Nesse modelo, o conhecimento é socialmente construído e a sustentabilidade é resultado da integração entre os agentes locais e agentes externos, de órgãos oficiais ou não. O caminho da sustentabilidade exige mudanças de comportamento em todos os elos envolvidos, as comunidades locais devem estar abertas e receptivas a novos conceitos e metodologias, e a comunidade científica deve ouvir e perceber o conhecimento tradicional.

Assim, é necessário desenvolver, através de processos de educação e conscientização, uma visão holística que contemple a interação entre homem e meio, bem como promover a união e integração dos setores governamentais, não governamentais e das comunidades locais, visando à implantação, orientação e assistência técnica de projetos sustentáveis. Os projetos devem respeitar a aptidão e conhecimento tradicional de cada região e localidade, além de serem estabelecidos mecanismos de monitoramento para avaliações periódicas de programas e metas por todos os atores envolvidos.

\section{AGRADECIMENTOS}

A André Augusto Dias, Anuar Abussamra de Almeida, Arnaldo das Neves, Danilo Lima Dias, Dauro Prado, Edinaldo Hermínio da Silva , Glaciela Gomes, Lacerdo Rodrigues, Major, Marcelo Trudes e a todos os demais comunitários da Aldeia do Una e da Costeira da Barrs, pelo auxílio nos trabalhos de campo, pelas entrevistas e pela participação no seminário.

Revista Árvore, Viçosa-MG, v.34, n.6, p.1065.1073, 2010 


\section{REFERÊNCIAS}

ALBUQUERQUE, U. P. Etnobiologia e biodiversidade. Recife: NUPEEA/Sociedade Brasileira de Etnobiologia e Etnoecologia, 2005a. 78p.

ALBUQUERQUE, U. P. Introdução à etnobotânica. 2.ed. Rio de Janeiro: Interciência, 2005b. 93p.

ADAMS, C. Caiçaras na Mata Atlântica: pesquisa científica versus planejamento e gestão ambiental. São Paulo: Annablume/FAPESP, 2000. 338p.

ARRUDA, R. Populações tradicionais e a proteção dos recursos naturais em unidades de conservação. Ambiente \& Sociedade, v.2, n.5, p.79-92, 1999.

ARRUDA, R. Populações tradicionais e a proteção dos recursos naturais em unidades de conservação. In: DIEGUES, A. C. S. (Org).

Etnoconservação: novos rumos para a proteção da natureza nos trópicos. São Paulo: Annablume/NUPAUB/HUCITEC, 2000. p.273-290.

AZEVEDO, C. M. A. A regulamentação do acesso aos recursos genéticos e aos conhecimentos tradicionais associados no Brasil. Biota Neotropica, v.5, n.1. Disponível em: $<$ (http://www.biotaneotropica.org.br) Assesado em: 2005.

BENSUSAN, N. Conservação da biodiversidade em áreas protegidas. Rio de Janeiro: FGV, 2006. 176 p.

BOTREL, R. T. et al. Uso da vegetação nativa pela população local no município de Ingaí, MG, Brasil. Acta Botânica Brasílica, v.20, n.1, p.143-156, 2006.

CALVI, G. P.; TERRA, G.; PIÑA-RODRIGUES, F. C. M. Germinação e estabelecimento de sementes de Euterpe edulis - Mart. Em floresta ombrófila densa montana no município de Miguel Pereira RJ. Revista Universidade Rural, v.24, n.1, p.107-113, 2004.

CALVI, G. P.; PIÑA-RODRIGUES, F. C. M. Fenologia e produção de sementes de Euterpe edulis - Mart. Em trecho de floresta de altitude no município de Miguel Pereira - RJ. Revista Universidade Rural, v.25, n.1, p.33-40, 2005.
CANELADA, G. V. M.; JOVCHELEVICH, P. Manejo agroflorestal das populações tradicionais na Estação Ecológica Juréia-Itatins. Revista Instituto Florestal, v.3, p.913-920, 1992.

CAVALCANTI, C. Uma tentativa de caracterização da economia ecológica. Ambiente \& Sociedade, v.7, n.1, p.149-156, 2003.

DIEGUES, A. C. S. O mito moderno da natureza intocada. São Paulo: Hucitec/ NUPAUB USP, 2004. 161p.

DIEGUES, A. C. S.; VIANA, V. M. (Orgs).

Comunidades tradicionais e manejo dos recursos naturais da Mata

Atlântica. 2.ed. São Paulo: HUCITEC/NUPAUB/ CEC, 2004. 273p.

FANTINI, A. C.; GURIES, R. P. Forest structure and productivity of palmiteiro (Euterpe edulis Martius) in the Brazilian Mata Atlântica. Forest Ecology and Management, v.242, n.2-3, p.185-194, 2007.

GALETTI, M.; FERNANDEZ, J. C. Palm heart harvesting in the Brazilian Atlantic Forest: changes in industry structure and the illegal trade. Journal of Applied Ecology,v.35, n.2, p.294-301, 1998.

GALETTI, M.; ALEIXO, A. Effects of palm heart harvesting on avian frugivores in the Atlantic rain forest of Brazil. Journal of Applied Ecology, v.35, n.2, p.286-293, 1998

GOMES, A. N. et al. Sustentabilidade de empresas de base florestal: o papel dos projetos sociais na inclusão das comunidades locais. Revista Árvore, v.30, n.6, p.951-960, 2006.

HEIDEN, G.; BARBIERI, R.; STUMPF, E. R. T. Considerações sobre o uso de plantas ornamentais nativas. Revista Brasileira de Horticultura Ornamental, v.12, n.1, p.2-7, 2006.

LIMA, G. S.; RIBEIRO, G. A.; GONÇALVES, W. Avaliação da efetividade de manejo das unidades de conservação de proteção integral em Minas Gerais. Revista Árvore, v.29, n.4, p.647-653, 2005.

LINO, C. F. Reserva da Biosfera da Mata Atlântica: plano da ação. Referências básicas. Campinas: Universidade de Campinas, 1992. v.1.101p. 
MARCOS, C. S.; MATOS, D. M. S. Estrutura de populações de palmiteiro (Euterpe edulis Mart.) em áreas com diferentes graus de impactação na Floresta da Tijuca, RJ. Floresta e Ambiente, v.10, n.1, p.27-37, 2003.

MARTINS, S. V.; LIMA, D. G. Cultura de palmeiras I: Palmiteiro (Euterpe edulis Mart.). Viçosa, MG: Universidade Federal de Viçosa, 1999. 28p.

MAX, J. C. M. et al. Plano de desenvolvimento sustentável para o entorno da Estação Ecológica de Assis. Revista do Instituto Florestal - Série Registros, n. 32, p.1-48, 2007.

OLIVA, A.; MAGRO, T. C. A evolução do planejamento do entorno das unidades de conservação de proteção integral. In: CONGRESSO BRASILEIRO DE UNIDADES DE CONSERVAÇÃO, 4., 2004, Curitiba. Anais.. Curitiba: 2004. v.1. p.462-473.

OLIVEIRA, R. R. et al. Roça Caiçara: um sistema primitivo auto-sustentável. Ciência Hoje, v.18, n.104, p.44-51, 1994.

QUEIROZ, H. L. A Reserva de Desenvolvimento Sustentável Mamirauá. Estudos Avançados, v.19, n.54, p.183-203, 2005.
ROSSATO, S. C. Utilização de plantas por populações do Litoral Norte do Estado de São Paulo. 1996. 119f. Dissertação (Mestrado em Ecologia, Instituto de Biociências) Universidade de São Paulo, São Paulo, 1996

SACHS, I. Rumo a ecossocioeconomia. São Paulo: Cortez, 2007. 472p.

SALES, R. R. et al. Programa de regularização da exploração comercial do palmito juçara Euterpe edulis. In: DIEGUES, A.C.; VIANA, V.M. (Orgs.) Comunidades tradicionais e manejo dos recursos naturais da Mata Atlântica. São Paulo: Hucitec/NUPAUB/USP, 2004. p.81-88.

SANCHES, R. A. Caiçaras e a Estação

Ecológica de Juréia-Itatins, Litoral Sul, São Paulo. São Paulo: FAPESP/Annablume, 2005. 207p.

SILVA, H. et al. Pressões antrópicas em áreas protegidas: desafios para conservação no Século XXI. CONGRESSO BRASILEIRO DE UNIDADES DE CONSERVAÇÃO, 4., 2004, Curitiba. Anais.. Curitiba: 2004. p.673-680.

SCARANO, F. R. Perspectives on the biodiversity sciences in Brazil. Scientia Agricola v.64, n.4, p.439-447, 2007.

THIOLLENT, M. Metodologia da pesquisaação. 15.ed. São Paulo: Cortez, 2007. 132p. 